\section{History of the Speaking Telephone}

As the writer of the article on the history of the telephone, to which so eminent an authority as Prof. Watson takes exception in the long and interesting letter he has contributed to your columins, perhaps yon will allow me to say a few words. Prof. Watson expresses his " astonishment at the claim now made that he (Mr. Gray) anticipated Mr. Bell in the invention of the spealing telephone," and speaks of the "erroneous statement of facts" contained in the article in question (NATURE, vol. xviii. p. 696). Unfortunately Prof. Watson has not specified the statements which are erroneous, and appears to have overlooked the fact that the article is a review of the works of Mr. Prescott and M. du Moncel on the telephone, and that the "statements of facts" are chiefly quotations from those works. At the same time, using all the materials within my reach, careful inquiry had led me to concur, and in that article I expressed my concurrence in the following opinion, quoted from Count du Moncel's book :- "Si M. Bell a été le premier à construire et à rendre pratique le téléphone parlant, M. Elisha Gray avait le premier conçu le principe de cet instriment."

Gray and Bell were both exhibitors at the Philadelphia Exhibition, and Prof. Watson, writing as one of the judges of the scientific instruments exhibited, shows that whilst Gray merely submitted to the judges an apparatus for the multiple transmission of musical notes, and no spealing telephone, Bell not only exhibited a speaking telephone, but towards the end of June $(x 876)$ the judges, Prof. Watson and Sir William Thomson, obtained with Bell's instrument the clearest evidence of the electric transmission of speech ${ }^{1}$ whereupon Mr. Gray was both surprised and incredulous, and even after the publication of Prof. Bell's discovery, he delivered a lecture exhibiting his musical telephone, but making no mention of a speaking telephone.

If the Philadelphia Exhibition were the only means for scien tific publication during the year it :existed, Prof. Watson's letter would effectually dispose of Gray's claim. An exhibition, how ever, is not the place for conceptions, but for accomplished facts, and I believe no one denies that to $\mathrm{Mr}$. Bell is due all the credit of having been the first to construct, and that entirely independently of Gray, an articulating electric telephone. Gray's claim, as I talie it, rests on his having registered in the American Patent Office, on February 14, 1876, "a means of transmitting and receiving vocal sounds telegraphically," and the drawing he gives of his invention shows a correct appreciation of the true principle of an articulating teleplione, to which his previous researches had been gradually leading him.

I should be sorry to appear in any way to depreciate the splendid achievement of Prof. Bell through having referred to other workers in the field of electric-telephony. In fact up to the time the article in NATURE appeared, I fear that, through ignorance, I had done but scant justice to $\mathrm{Mr}$. Gray, having attributed the conception of the principle of an articulating tele phone solely to Prof. Graham Bell.

There are two points in the history of the telephone upon which $I$ should be very glad to have authoritative information from Prof. Watson or other of your American readers; the first relates to the claim made by Prof. Dolbear, and the second to the introduction of the ferrotype diaphragm. W. F. BARRETr?

Royal College of Science, Dublin, December 9

\section{The Formation of Mountains}

IN the account of M. Favre's experiments in NATURE, vol. xix. p. IO3, I find the following passage :- "It is, in fact, very probable that our globe is at the stage when, according to klie de Beaumont, "the mean annual cooling of the mass exceeds that of the surface, and exceeds it more and more.' It must follow that the external strata of the globe, tending always to rest on the internal parts, are wrinkled, folded, dislocated, depressed at certain points, and elevated at others."

The whole theory of these dislocations, \&c., thus depends on the assumption that the interior of the globe is cooling more rapidly than the crust. This has always seemed to me au im possibility, and even an absurdity, and I shall be very glad if any of your correspondents will explain how it is possible. I have always understood that the surface of the earth does not

I I am glad to learn the exact clate of the trial in questicn, which was given as August in the article. now derive any appreciable portion of its heat from the in. terior; but if the interior is cooling rapidly, to what can it part with its heat but to the crust? Volcanoes and hot springs no doubt allow a certain portion of heat to escape, but it must be an infinitesimal part of the heat of the entire mass. If the meaning of the statement is, that the heat received froun the sun now lieeps the surface at a permanent mean temperature, quite irrespective of central heat or cold, and that therefore the loss of heat by volcanoes, \&c., causes the centre to cool while the crust does not-this may be admitted, but it is doubtful whether it can have any bearing on the effects observed. For, on this theory, all the compression would take place in that shallow superficial layer which is kept above its normal temperature by the sun's radiation; and as we go back into past time this superficial layer would be thinner and thinner. But all geological evidence goes to show that folded and contoried rocks were subject to com. pression at considerable deptbs; and further, that such contortion was greater in comparatively early than in very late geological times-both facts directly opposed to the theory in question. Will any one of our great physicists enlighten us?

ALFRED R. WALLACE

AfTer reading your résumé of Prof. Alphonse Favre's interesting experiments on the formation of mountains by lateral thrust, it occurred to me that it would be easy to devise a mode of experimenting which would more nearly correspond with what takes place in nature. In $M$. Favre's experiments the lateral thrust was simply in one direction. In nature it is in all directions.

If a disk of india-rubber were stretched by means of a steel ribbon bent into a circular spring, on letting the spring slowly recoil there would be a lateral contraction of the india-:ubber in all directions. A lager of clay upon that disk would, I think, show not the transverse inequalities of M. Favre's drawings, but a diversified unevemess more nearly resembling the actual surface of the earth.

Leicester, December

ARTHUR RANSOM

\section{New Galvanometer for Strong Currents}

I OBSERVE in NATURE (vol. xviii. p. 707) an article on a new calvanometer for strong currents by Mr. Eugen Obach. I. pub lished a paper on the same form of galvanometer seven years ago, and inclose a copy of my paper which was published in the American foumal of Arts and Sciences, vol. ii., August, $187 x$.

TOHN TROWBRIDGE

Harvard College, Cambridge, Mass., U.S.A., November 23

\section{Explanatory}

I Must ask you, in common fairness, to allow we to protesi against P. G. 'T.'s mistaken statement (vol, xix, p. 71) respecting a sentence which he quotes without the explanatory context. The moving force exeited by the earth on the moon as a whole is of course precisely equal to the moving force exerted by the moon on the earth. I had not to learn this from P. G. T., but had said so in so many words. But the moving force exerted by the earth on a given amount of matter in the moon is eighty-one times greater than the moving force exerted by the moon on an equal amount of matter in the earth. P. G. T. will scarcely deny this, and he cannot deny that the whole statement from which he quotes one sentence meant this, and this only. Nor, if he did, would any one who has read the clapter on the moon's motions in my treatise on the moon, believe such a statement.

He quotes a passage from my last book without comment, but, unfortunately, not without serious alteration. Apart from the andue emphasis which he thus gives to certain parts of it, the passage expresses my honest opinion. That I may be mistaken is quite possible. Men are always misunderstanding each other. If I find I have erred, I will acknowledge as much.

Until the word "heat" ceases to be used in common speech in two senses, or I am shown that when used for "temperature" (as when we say blood heat, boiling heat, a heat of $90^{\circ} \mathrm{F}$., and so forth), it can be understood to mean "caloric," I intend always so to use it in familiar writing about science. I deliberately struck out the word "temperature" wherever I had used it, and replaced it by the word "heat," in the same way and for the same reason that I often replace the word "velocity" by the 